Article

\title{
Numerical Investigation of Small-Scale Adsorption Cooling System Performance Employing Activated Carbon-Ethanol Pair
}

\author{
Marzia Khanam ${ }^{1,2}$, Skander Jribi ${ }^{3, *(\mathbb{D})}$, Takahiko Miyazaki ${ }^{1,2, *}$, Bidyut Baran Saha ${ }^{2}(\mathbb{D})$ and \\ Shigeru Koyama ${ }^{1,2}$ \\ 1 Interdisciplinary Graduate School of Engineering Sciences, Kyushu University, Kasuga-koen 6-1, Kasuga-shi, \\ Fukuoka 816-8580, Japan; marzia@phase.cm.kyushu-u.ac.jp (M.K.); koyama@cm.kyushu-u.ac.jp (S.K.) \\ 2 International Institute for Carbon-Neutral Energy Research, Kyushu University, 744 Motooka, Nishi-ku, \\ Fukuoka-shi, Fukuoka 819-0395, Japan; saha.baran.bidyut.213@m.kyushu-u.ac.jp \\ 3 Laboratory of Electro-Mechanical Systems, National Engineering School of Sfax, University of Sfax, \\ Route Soukra km 3.5, Sfax 3038, Tunisia \\ * Correspondence: skander.jribi@gmail.com (S.J.); miyazaki.takahiko.735@m.kyushu-u.ac.jp (T.M.); \\ Tel.: +216-55-189-636 (S.J.); +81-80-5447-0478 (T.M.)
}

Received: 1 May 2018; Accepted: 29 May 2018; Published: 8 June 2018

\begin{abstract}
Adsorber heat exchanger design has great importance in increasing the performance of the adsorption-based cooling system. In this study, a transient two-dimensional axisymmetric Computational Fluid Dynamics (CFD) model has been developed for the performance investigation of finned tube type adsorber using activated carbon and ethanol as the working pair. The operating conditions of the cooling system were 15, 20 and 80 for evaporation, cooling and heating temperatures, respectively. The simulated temperature profiles for different adsorbent thicknesses were validated with those from experimental data measured in our laboratory. Moreover, the error in mass and energy balance were $3 \%$ and $7.88 \%$, respectively. Besides, the performance investigation has been performed for cycle time ranging from $600 \mathrm{~s}$ to $1400 \mathrm{~s}$. The optimum cycle time was $800 \mathrm{~s}$ and the corresponding evaluated specific cooling power (SCP) and coefficient of performance (COP) were found to be $488 \mathrm{~W} / \mathrm{kg}$ and 0.61 , respectively. The developed CFD model will be used for fin height and fin pitch optimization and can be extended to other adsorbent-adsorbate based adsorption cooling system.
\end{abstract}

Keywords: CFD; activated carbon; ethanol; finned tube adsorber; adsorption cooling; performance investigation

\section{Introduction}

Refrigeration is an important sector for the growing and sustainable global economy. It contributes significantly to food and drug conservation, thermal comfort, etc. However, greenhouse gas (GHG) emissions from this sector represent $7.8 \%$ of total emissions. Conventional refrigeration system employs refrigerants with high global warming potential (GWP) such as Chlorofluorocarbons (CFCs), hydrochlorofluorocarbons (HCFCs) and hydrofluorocarbons (HFCs) gases which produced $37 \%$ of the emissions and the remaining $63 \%$ was caused indirectly by the energy consumption of cooling and air conditioning systems [1].

In this context, adsorption cooling systems (ACS) are a feasible alternative to vapor compression cooling systems. In fact, they are driven by low-grade waste heat (below $100^{\circ} \mathrm{C}$ ) or solar thermal energy [2,3]. Moreover, they employ natural and environment-friendly refrigerants such as water $[4,5]$, ethanol [6], methanol [7,8], ammonia [9], $\mathrm{CO}_{2}$ [10], etc. Therefore, the widespread development 
of adsorption cooling system will help to solve various energy and environment-related problems. Besides, in summer, when cooling demand goes to highest pick and gives stress to the electric grid, thermally driven sorption cooling systems will alleviate the electric grid pick [11].

Although ACS has several advantages, it is often impaired by low performance and bulkiness issues comparing to conventional vapor compression systems. Consequently, these issues hinder the widespread commercialization of thermally driven ACS [12]. Therefore, one of the big challenges for ACS is how to increase the system performance. The performance of ACS is commonly evaluated using two parameters, namely the coefficient of performance (COP) and specific cooling power (SCP) [13]. The higher the COP and SCP, the higher the system performance is. To improve the performance of the system, one of the key ways is to enhance the heat and mass transfer inside the adsorber bed, thus accelerating the adsorption and desorption process. Adsorber heat exchanger design improvement and thermal conductivity enhancement of adsorbent are two common techniques to ensure good heat transfer inside the bed [14].

Adsorber bed design optimization is very difficult to perform experimentally due to the high cost and huge time requirement. Several researchers [15-18] have performed simulations to investigate the performance of ACS for different adsorbent-adsorbate pairs with lump-sum modeling. Though these simulations provide more realistic performance comparing to ideal cooling cycle performance, however, the assumptions in that modeling such as the same temperature in the bed are not realistic.

In contrast, CFD simulation can provide detailed heat and mass transfer distributions inside the adsorber bed. Moreover, CFD simulations can provide faster bed design at lower cost to realize higher SCP and COP. Due to the several advantages associated with CFD simulation, it has accrued a lot of interest recently. A transient two-dimensional simulation of combined heat and mass transfer in the adsorber bed of a silica gel-water adsorption cooler was presented by Niazmand and Dabzadeh [19]. The authors showed the effect of fin height, fin spacing and cycle time on COP and SCP for an annular fin adsorber. A three dimensional non-equilibrium model of combined heat and mass transfer employing water and composite sorbent SWS-1L has been developed by Mahdavikhah and Niazmand [20] to predict the dynamic performance of ACS. The authors examined the effects of plate fin heat exchanger configurations on the system performance and they mentioned that adsorber bed geometry has a great importance in designing ACS. Ramji et al. [21] presented three-dimensional modeling and CFD simulations of an activated carbon-methanol adsorber for mobile air-conditioning applications. A two-dimensional CFD simulation has been performed for silica-gel water pair by Caglar. The author showed the comparison of adsorbent bed with fin and finless tubes. Besides, the influences of various fin configurations on heat transfer inside the bed have studied by the author [22].

However, from the literature it is found that very few CFD simulation works have been done on the activated carbon and ethanol pair. Recently, Jribi et al. [23] showed the temperature change in the activated carbon packed heat exchanger during the adsorption process. Besides, the author showed the temperature profile with and without the heat of adsorption. Sourav et al. [24] reported the effects of heat exchanger aspect ratio and adsorbent particle size on the dynamic adsorption characteristics. However, in both cases, the authors did not show the simulation results for all cycle phases such as adsorption, pre-heating, desorption and pre-cooling process which is very important to investigate the adsorption system performance accurately. Moreover, the authors did not address the effect of cycle time in their study.

This study presents the mathematical model and transient CFD simulation of finned tube type adsorber/desorber bed employing activated carbon-ethanol pairs for adsorption cooling applications. Simulation results are compared with experimental data for all the adsorption cycle phases considering similar operating conditions. Good agreement is found between the experimental and simulated temperature and pressure profiles. Moreover, heat and mass balance are examined for the system. Finally, performance optimization is done based on cycle time ranging from $600 \mathrm{~s}$ to $1400 \mathrm{~s}$. The optimum cycle time was reported $800 \mathrm{~s}$ and the corresponding evaluated SCP and COP were found to be $488 \mathrm{~W} / \mathrm{kg}$ and 0.61 , respectively. Besides cycle time, our developed CFD model can 
be used to optimize the operating conditions and adsorber heat exchanger configurations such as fin pitch, fin height and fin thickness. Moreover, this developed model can be extended for other adsorbent-adsorbate pairs.

\section{Working Principle of Adsorption Cooling System}

Figure 1 shows the schematic diagram of a one-bed adsorption cooling system. It generally consists of four components: a condenser, an evaporator, an adsorber/desorber bed filled with the activated carbon powder (ACP) and an expansion valve. An adsorption cycle comprises four processes, which are pre-heating, desorption, pre-cooling and adsorption. In the pre-heating process, the bed is disconnected from the evaporator and hot water is circulated in the adsorption bed to increase the bed pressure. When bed pressure becomes higher than that in the condenser, then it is connected to the condenser and desorption process starts. Ethanol vapor is desorbed from activated carbon bed to the bed because of additional heating and moves to the condenser where it condenses. After the desorption is finished, the bed is disconnected from the condenser and cooling water is circulated in the adsorber bed which is called pre-cooling process. Due to the cooling water supply, the pressure in the bed decreases and becomes lower than that in the evaporator. At this moment, the adsorber bed is connected to the evaporator and evaporated ethanol vapor comes out of the adsorber and is adsorbed in the activated carbon bed. During the adsorption process, cooling water is supplied to the bed continuously to remove the heat of adsorption.

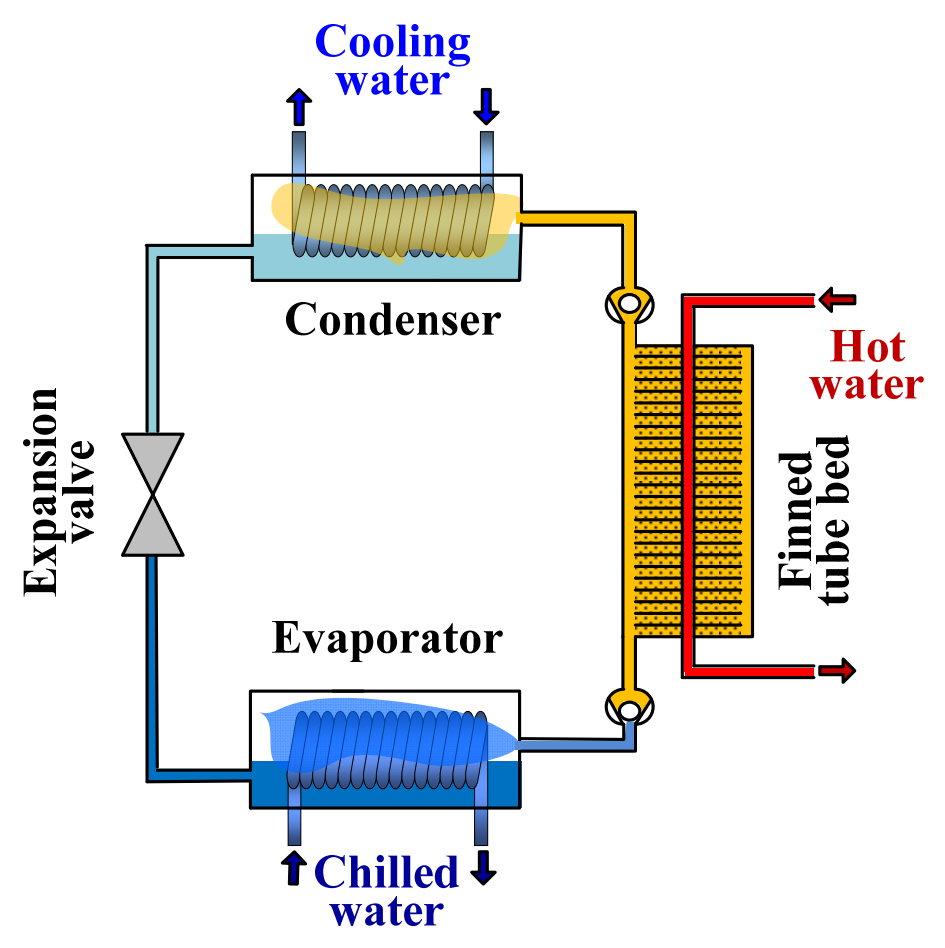

Figure 1. Schematic of adsorption cooling system in desorption process.

\section{CFD Modeling}

Performance investigation of finned tube type adsorber employing activated carbon and ethanol pairs was carried out experimentally in our laboratory earlier $[25,26]$. The experimental apparatus consists of an adsorber, an evaporator and a condenser connected with stainless steel tubes. The temperatures and pressures in all components are measured by K-type thermocouples and pressure gages, respectively. Two copper finned tubes were incorporated inside the adsorber. The finned tube heat exchanger consists of 190 circular fins attached to an annular tube having a length of $700 \mathrm{~mm}$. Fin height, fin pitch and fin thickness were 10, 3.7 and $0.53 \mathrm{~mm}$, respectively. Porous activated carbon was 
filled between two consecutive fins and sealed with a mesh sheet. The annular tube was $1.5 \mathrm{~mm}$ thick with an inner diameter of $26 \mathrm{~mm}$. Ethanol was considered as refrigerant. Besides, water was used as a heat transfer fluid and passed through the annular tube. The adsorbent temperatures at 1 and $5 \mathrm{~mm}$ thicknesses were recorded experimentally by using K-type thermocouples shown as $\mathrm{T}_{1}$ and $\mathrm{T}_{5}$ in Figure 2.

Under similar experimental conditions, the transient CFD simulation was performed using Ansys-Fluent software v.18.1 (ANSYS, Canonsburg, PA, USA). Geometry and meshing were created by using Ansys Design Modeler and Ansys Meshing, respectively. The details of the CFD modeling were presented as follows:

\subsection{Assumptions}

The assumptions used in the simulation are as follows:

- The adsorbent layer height is equal to the height of the fins.

- The porous media is considered as homogenous.

- Darcy model is adopted for flow through porous media.

- A thermal equilibrium model is assimilated for porous media i.e., the adsorbent and ethanol vapor are at same temperature.

- The variation of the heat of adsorption with the ethanol uptake is not considered, therefore, the average value of the heat of adsorption is used.

\subsection{Geometry and Meshing}

Figure 2 shows the finned tube geometry and computational domain. The finned tube heat exchanger has a symmetric axis; therefore, the geometry is reduced to 2D. Besides, the computational domain used in the simulation is the half space between the two fins as this geometry has several symmetry planes.

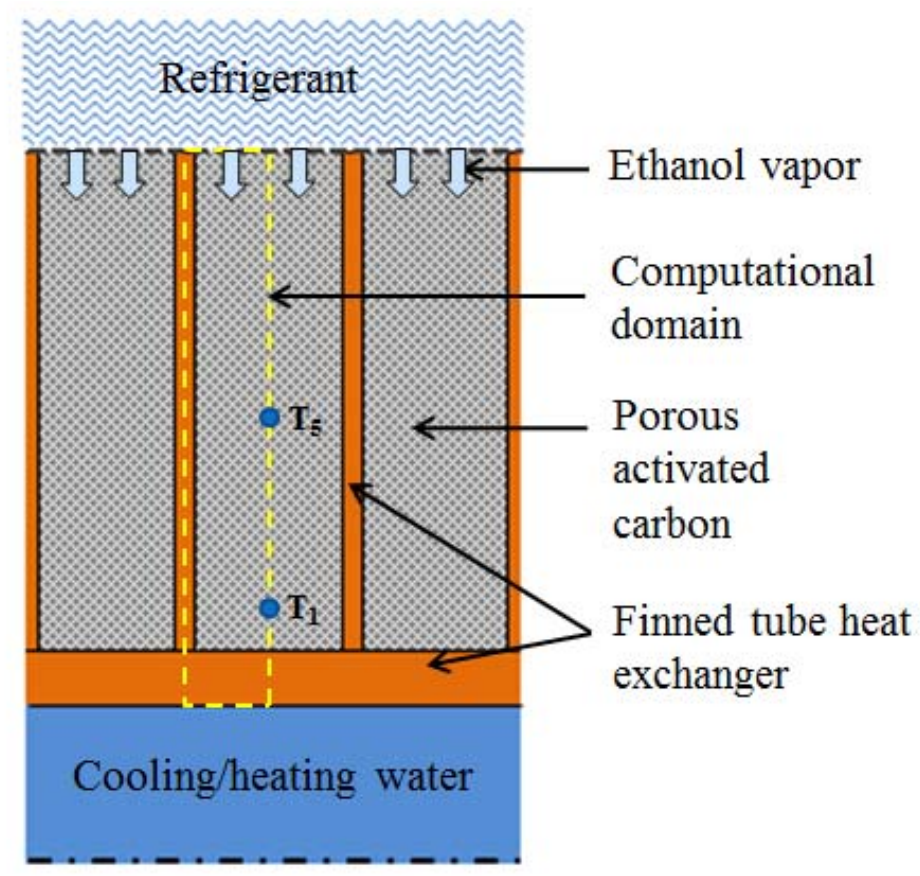

Figure 2. 2D-axisymmetric geometry of the finned tube adsorber showing computational domain. 
To perform the simulation, we used fine meshing and divided the computational domain $(11.5 \mathrm{~mm} \times 1.85 \mathrm{~mm})$ into 748 elements with 897 nodes. The following mesh quality is reported from Fluent:

- $\quad$ Minimum orthogonal quality $=0.9721$ where orthogonal quality ranges from 0 to 1 and values close to 0 represents low quality.

- $\quad$ Maximum ortho skew $=0.0279$ where ortho skew ranges from 0 to 1 and values close to 1 correspond to low quality.

\subsection{Materials and Porous Zone Properties}

\subsubsection{Materials}

The materials used in the simulations were: (i) copper tubing for tubes and fins, (ii) ethanol as gas phase refrigerant, and (iii) activated carbon powder of type Maxsorb III packed between the fins. The properties of copper were taken from the Fluent database. Real gas properties of ethanol were imported into Fluent from NIST Refprop database (v.9.1, NIST, Gaithersburg, MD, USA). The properties of Maxsorb III were, the particle density $\rho_{p}=464.1 \mathrm{~kg} \cdot \mathrm{m}^{-3}$, adsorbent-adsorbate thermal conductivity $k_{p}=0.2 \mathrm{~W} /(\mathrm{m} \cdot \mathrm{K})$ [23] and specific heat capacity. The solid adsorbent heat capacity of Maxsorb III was investigated lately and the average value for temperatures ranging from 30 to $80^{\circ} \mathrm{C}$ is $0.9 \mathrm{~kJ} /(\mathrm{kg} \cdot \mathrm{K})$ [27]. Therefore, the particle heat capacity for average instantaneous uptake of $0.7 \mathrm{~g} / \mathrm{g}$ considering that the adsorbate is in the liquid phase [28] becomes $4.64 \mathrm{~kJ} /(\mathrm{kg} \cdot \mathrm{K})$.

\subsubsection{Porous Zone Properties}

The permeability $(\alpha)$ and inertial loss coefficient $(C)$ of porous media were calculated for the average particle diameter of Maxsorb III $D_{P}=70 \mu \mathrm{m}$ and adsorbent porosity $\gamma=0.434$ [23] by the following equations [29]. The viscous flow resistance inside the porous media is the reciprocal of permeability of adsorbent:

$$
\begin{gathered}
\alpha=\frac{D_{p}{ }^{2}}{150} \frac{\gamma^{3}}{(1-\gamma)^{2}} \\
C=\frac{3.5}{D_{P}} \frac{(1-\gamma)}{\gamma^{3}}
\end{gathered}
$$

\subsection{Boundary Conditions}

The boundary conditions applied in this simulation are shown in Figure 3 and the detailed boundary conditions are explained in Sections 3.4.1 and 3.4.2.

\subsubsection{Pressure Inlet/Wall/Pressure Outlet Conditions}

The interface between activated carbon and refrigerant is set as pressure inlet during adsorption process and the refrigerant inlet pressure was set to $3.85 \mathrm{kPa}$ corresponding to evaporation temperature of $13.1^{\circ} \mathrm{C}$. Similarly, the interface is considered as pressure outlet during the desorption process. In addition, desorption is performed at a pressure of $10.35 \mathrm{kPa}$ corresponding to the condensation temperature of $29.8^{\circ} \mathrm{C}$. Besides, at the time of preheating and precooling processes, the interface is considered as wall condition. The purpose of precooling is to reduce the bed pressure from condensation pressure to that of evaporation pressure. Therefore, when the bed pressure becomes lower than the evaporator's pressure, the precooling process was ended. Similarly, when the bed pressure becomes higher than that of condenser, the preheating process was terminated.

\subsubsection{Convection Boundary Conditions}

We applied convection boundary condition at the tube inner surface. The water temperature was estimated from the average of inlet and outlet temperature of the tube as presented in Figure 4 . The 
free stream temperature profile was fitted to polynomial functions and implemented into fluent as a user-defined function (UDF). Moreover, Gnielinski correlation [30] is used to calculate the convection heat transfer coefficient for water flow rate of $3 \mathrm{~L} / \mathrm{min}$. Then, the heat transfer coefficient is incorporated into fluent as a UDF for the temperature range $20{ }^{\circ} \mathrm{C}$ to $80{ }^{\circ} \mathrm{C}$. The heating and cooling processes were applied for $400 \mathrm{~s}$ each.

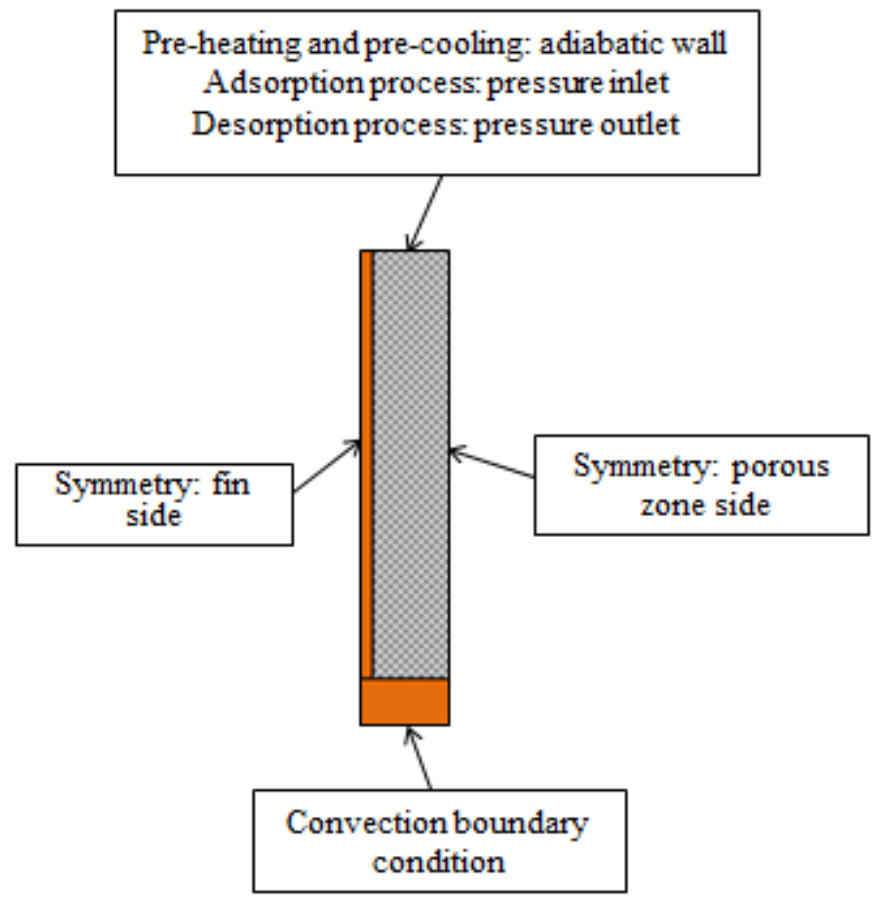

Figure 3. Domain boundary conditions.

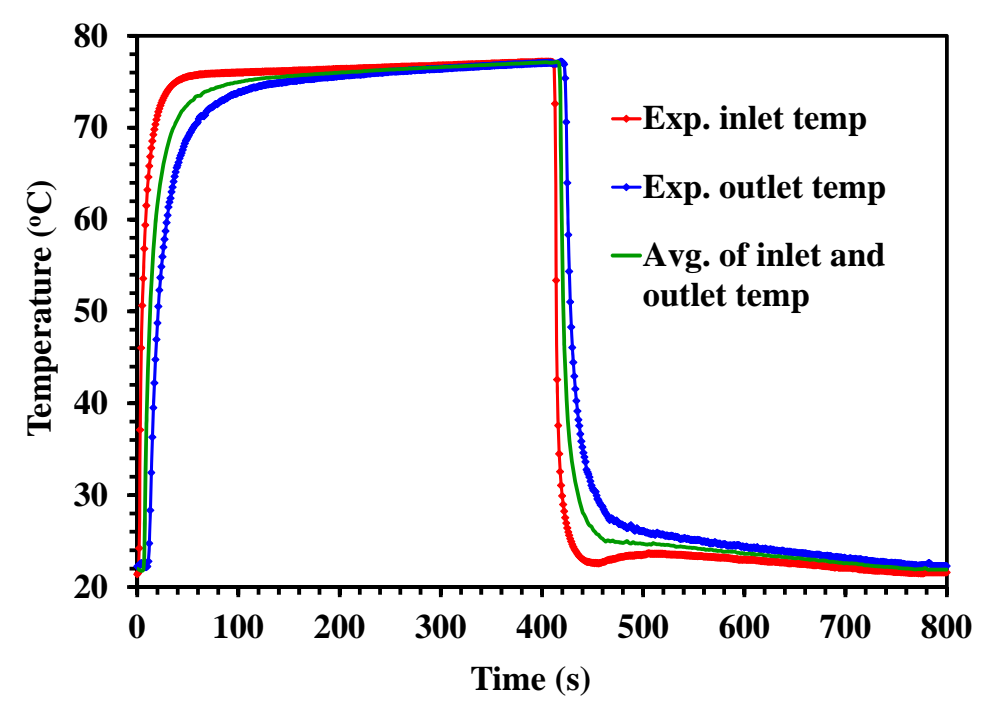

Figure 4. Water source temperature profiles at the inlet (red) outlet (blue) and middle tube (green).

\subsection{Governing Equations}

The main mathematical equations used in fluent are mass, momentum and energy conservation equations. To consider the adsorption phenomena, mass and energy source terms are added to these conservation equations through user-defined functions (UDFs). 


\subsubsection{Mass Conservation Equation in Porous Media}

The mass conservation equation for porous media is given by:

$$
\frac{\partial\left(\gamma \rho_{g}\right)}{\partial t}+\nabla \cdot\left(\rho_{g} \vec{v}\right)=S_{m}
$$

where the mass source term $\left(S_{m}\right)$ denote the adsorbed ethanol gas inside the porous media and is specified as follows:

$$
S_{m}=-(1-\gamma) \rho_{p} \frac{d q}{d t}
$$

The term $\frac{d q}{d t}$ represents the adsorption rate due to the diffusion of ethanol vapor through the Maxsorb III micro-pores which will be stated in Section 3.5.4.

\subsubsection{Momentum Conservation Equation}

The momentum conservation equation for porous media is expressed by:

$$
\frac{\partial}{\partial t}\left(\rho_{g} \vec{v}\right)+\nabla \cdot\left(\rho_{g} \vec{v} \vec{v}\right)=-\nabla p+\nabla \cdot \overline{\bar{\tau}}+\rho_{g} \vec{g}+\vec{F}
$$

where the momentum source term $(F)$ is estimated for the viscous and inertial losses in porous media.

$$
F_{i}=-\frac{\mu}{\alpha} v_{i}-\frac{1}{2} \rho_{g} C|\vec{v}| v_{i}
$$

The viscous resistance (inverse of permeability: $1 / \alpha$ ) and inertial losses coefficients were defined previously in Section 3.3.2:

\subsubsection{Energy Conservation Equation}

The energy conservation equation for porous media considering thermal equilibrium condition is given by:

$$
\frac{\partial}{\partial t}\left[\gamma \rho_{g} E_{g}+(1-\gamma) \rho_{p} E_{\mathrm{S}}\right]+\nabla \cdot\left[\vec{v}\left(\rho_{g} E_{g}+p\right)\right]=\nabla \cdot\left(k_{e f f} \nabla T\right)-\nabla \cdot \sum_{j} h_{j} \vec{j}_{j}+\nabla \cdot(\overline{\bar{\tau}} \cdot \vec{v})+S_{h}
$$

$S_{h}$ is the heat source term corresponding to the heat released by adsorption process and is given by:

$$
S_{h}=(1-\gamma) \rho_{p} Q_{s t} \frac{d q}{d t}
$$

Here, $Q_{s t}=1002 \mathrm{~kJ} / \mathrm{kg}$ is the average heat of adsorption for Maxsorb III-ethanol pair [31].

\subsubsection{Adsorption Characteristics}

The linear driving force (LDF) model [32] is used in this study to predict the adsorption kinetics $\left(\frac{d q}{d t}\right)$ and it is expressed by:

$$
\frac{d q}{d t}=k\left(q^{*}-q\right)
$$

where $k$ and $q^{*}$ are the diffusion time constant and equilibrium uptake, respectively. The diffusion time constant is defined by the Arrhenius equation (Equation (10)) and the equilibrium uptake was calculated by Dubinin-Astakhov (D-A) adsorption isotherm equation (Equation (11)):

$$
k=A \exp \left(-\frac{E_{a}}{R T}\right)
$$




$$
q^{*}=q_{s} \exp \left(-\left(\frac{R T}{E} \ln \left(\frac{P_{s}}{P}\right)\right)^{n}\right)
$$

$A=0.2415 \mathrm{~s}^{-1}, E_{a}=225 \mathrm{~kJ} / \mathrm{kg}, q_{s}=1.2 \mathrm{~kg} / \mathrm{kg}, E=139.5 \mathrm{~kJ} / \mathrm{kg}$ and $n=1.8$ denote the pre-exponential factor, activation energy, saturated uptake, characteristic energy and heterogeneity parameter, respectively [33].

In D-A equation, $P_{S}$ denotes the saturated pressure (bar) calculated by the Antoine equation:

$$
\log _{10} P_{s}=A-\frac{B}{T+C}
$$

where $A=5.247, B=1598.673$ and $C=-46.424$ are the constant parameters of Antoine equation for ethanol at the temperature range 292.77 to $366.63 \mathrm{~K}$ [34].

\subsubsection{Performance Investigation}

The performance of adsorption cooling system was investigated using Equations (13) and (14) to calculate specific cooling power (SCP) and coefficient of performance (COP), respectively:

$$
\begin{gathered}
S C P=\frac{h_{f g} \cdot \int_{a d s \_s t a r t}^{a d d \_e n d} \dot{m}_{a d s} d t}{t_{c y c l e} \cdot m_{a c}} \\
C O P=\frac{Q_{\text {chill }}}{Q_{\text {des }}}
\end{gathered}
$$

where:

$$
Q_{\text {chill }}=h_{f g} \cdot \int_{\text {ads_start }}^{\text {ads_end }} \dot{m}_{a d s} d t
$$

3.5.6. Mass and Energy Balance Equation

The mass balance in the adsorber/desorber bed implies that the mass of refrigerant adsorbed onto the adsorbent is equal to that desorbed from the bed as described in Equation (16):

$$
\int_{\text {ads_start }}^{\text {ads_end }} \dot{m}_{a d s} d t=\int_{\text {des_start }}^{\text {des_end }} \dot{m}_{\text {des }} d t
$$

The energy balance in the adsorption cooling system indicates that the heat released by the condenser and adsorber bed is equal to that adsorbed by the evaporator and desorber bed as expressed by the following equation:

$$
Q_{\text {chill }}+Q_{\text {des }}=Q_{\text {cond }}+Q_{a d s}
$$

\section{Results and Discussion}

\subsection{Pressure Profile}

Figure 5 shows the simulated pressure change vs. experimental pressure profile in the adsorber/desorber bed for two cycles. The experimental pressure was not constant during adsorption and desorption processes as it was affected by the temperature fluctuation in condenser and evaporator, respectively and this was not considered in this study. In the simulated pressure profile, adsorption and desorption occur at constant pressure condition as seen from Figure 5. Besides, the simulation can obtain the cyclic steady-state pressure within two cycles. Good agreement has been found between experimental and simulated pressure profiles at the beginning of pre-heating and pre-cooling processes. 


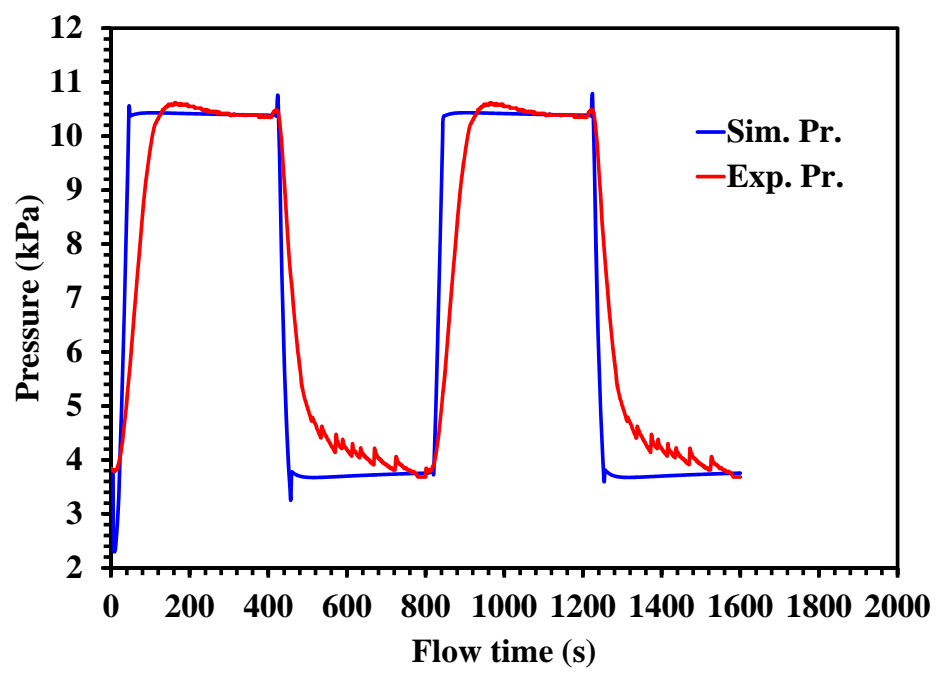

Figure 5. Comparison of pressure change in the adsorber/desorber bed: experimental (red) and simulated (blue).

\subsection{Temperature Profiles}

Experimental temperature change vs. simulated temperature profile at 1 and $5 \mathrm{~mm}$ adsorbent thicknesses $\left(T_{1}\right.$ and $\left.T_{5}\right)$ were presented in Figure 6. Good agreement was found between the experimental data and the simulated results. From Figure 6, simulated temperature profile perfectly matched with that of experimental data at the end of desorption and in pre-cooling process. However, a little deviation is found during the adsorption process and at the starting of desorption. One possible reason for deviation at adsorption process is that Gnielinski correlation under-estimated the heat transfer coefficient from the adsorber bed to the heat transfer water.

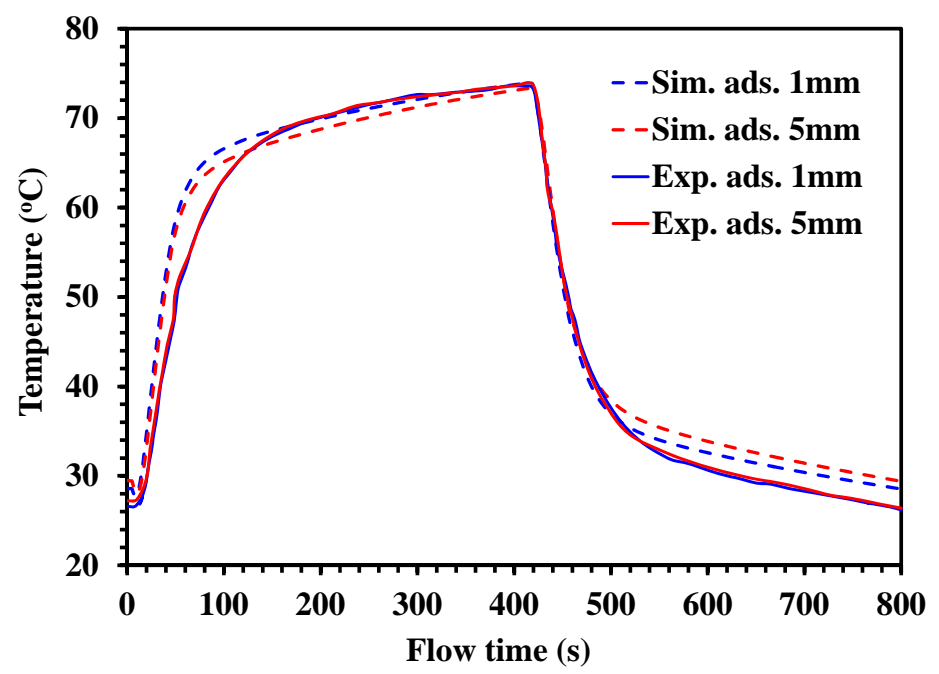

Figure 6. Simulated (dashed line) vs. experimental (line) temperature profiles at 1 (blue) and $5 \mathrm{~mm}$ (red) adsorbent thicknesses.

Figure 7 provides the simulated temperature profile at different adsorbent thicknesses from the tube outer surface such as $0,1,5$ and $8 \mathrm{~mm}$. During pre-heating and pre-cooling processes, the change of temperature is almost same in all these points due to high heat transfer rate. However, during desorption and adsorption process, the change of temperature is noticeable at 0,1 and $5 \mathrm{~mm}$ thickness. 


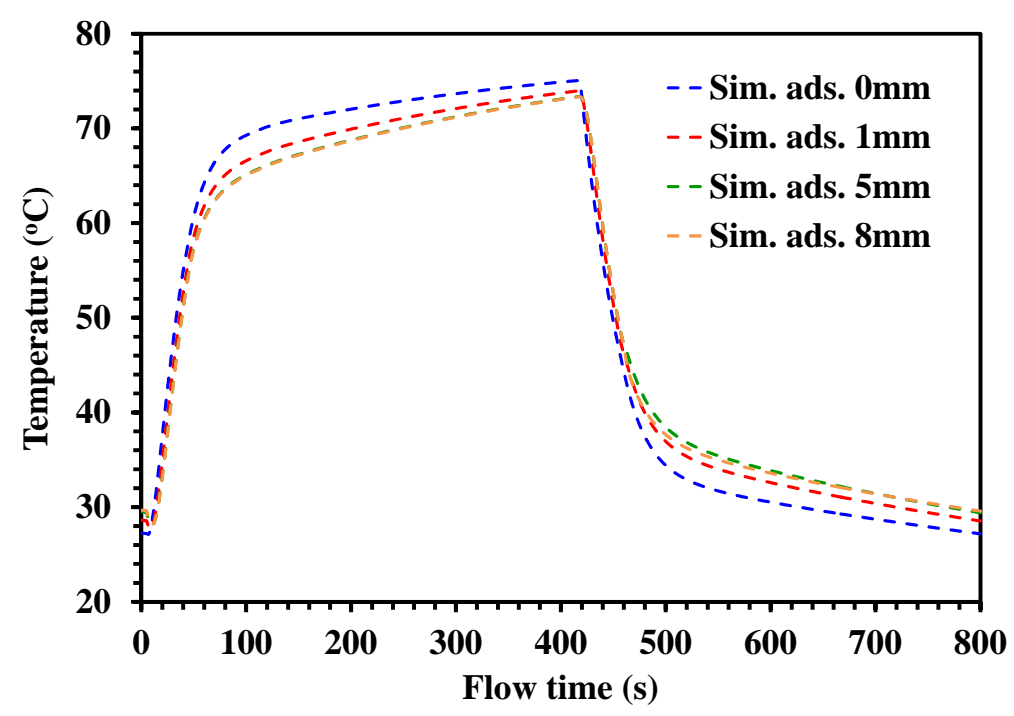

Figure 7. Simulated temperature profiles at different adsorbent thickness.

\subsection{Adsorption Characteristics}

The profiles of equilibrium uptake $\left(q^{*}\right)$ and instantaneous uptake $(q)$ in the adsorber/desorber bed are displayed in Figure 8. The difference between maximum and minimum values of equilibrium uptake $\Delta q^{*}$ is $0.51 \mathrm{~kg} / \mathrm{kg}$ whereas the change in case of instant uptake $\Delta q$ is $0.314 \mathrm{~kg} / \mathrm{kg}$. This means that ethanol adsorption onto activated carbon is only $61.6 \%$ of its capacity within the $400 \mathrm{~s}$ adsorption time.

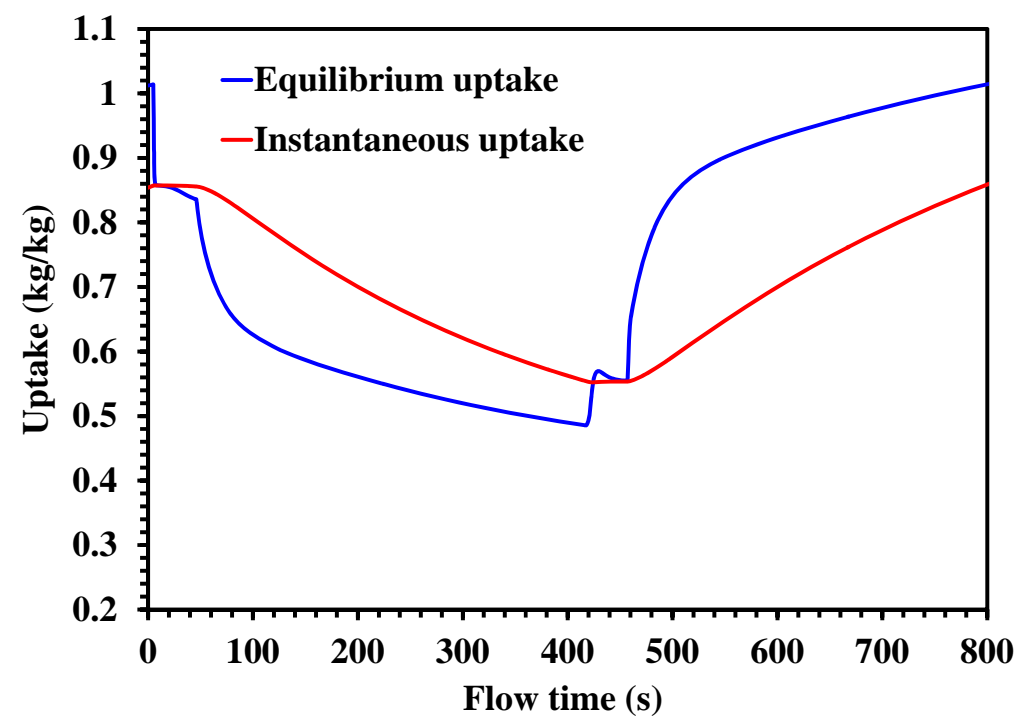

Figure 8. Simulated average instantaneous (red) and equilibrium (blue) uptakes in the adsorber/desorber bed.

\subsection{Energy and Mass Balance}

The total amount of heat removed from adsorber and that added to desorber were calculated by integrating the heat transfer profile as shown in Figure 9. The values of heat released from condenser and adsorber bed and those adsorbed by desorber and evaporator are used to check the energy balance as shown in Equation (17) and the error in energy balance is found to be $7.9 \%$. 
The simulated ethanol flow rate to/from the adsorber/desorber bed is presented in Figure 10. The error in mass balance was 3\% which is estimated by Equation (16).

One of the main reasons for mass balance error is that the time for adsorption and desorption was not exactly same in the case of the experiment. The time difference during the experiment was around $12 \mathrm{~s}$. This mass balance error also affects the energy balances. Besides, during adsorption at $20{ }^{\circ} \mathrm{C}$ temperature, the heat transfer coefficient was underestimated by Gnielinski correlation that is also visible in Figure 6. Therefore, heat input was higher than the heat removed from the bed.

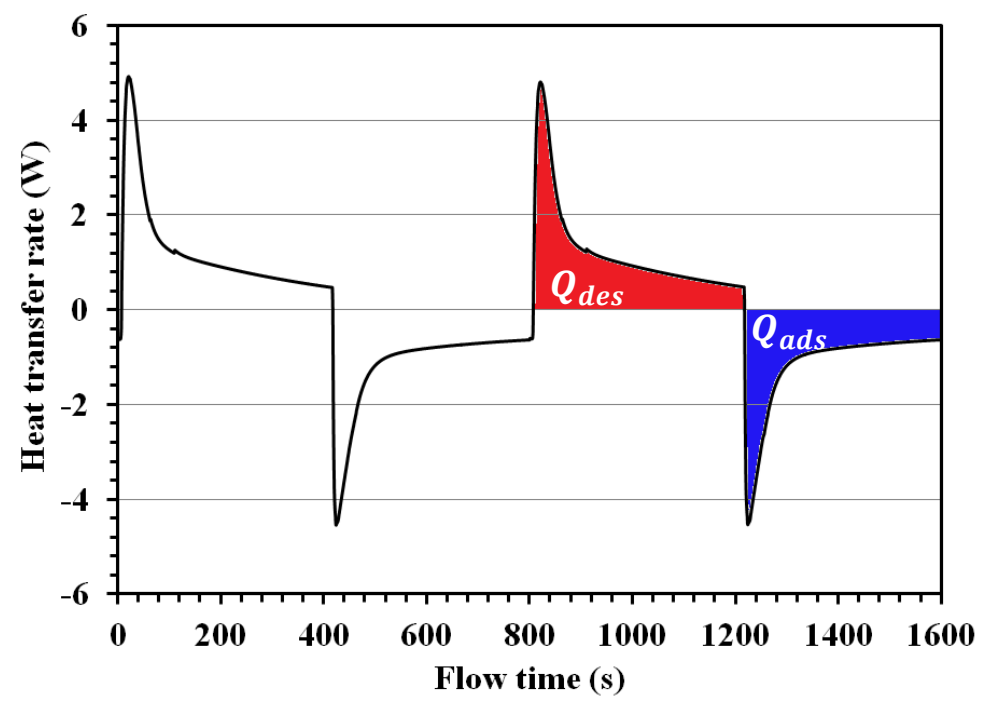

Figure 9. Simulated heat transfer rate to and from the finned tube adsorber.

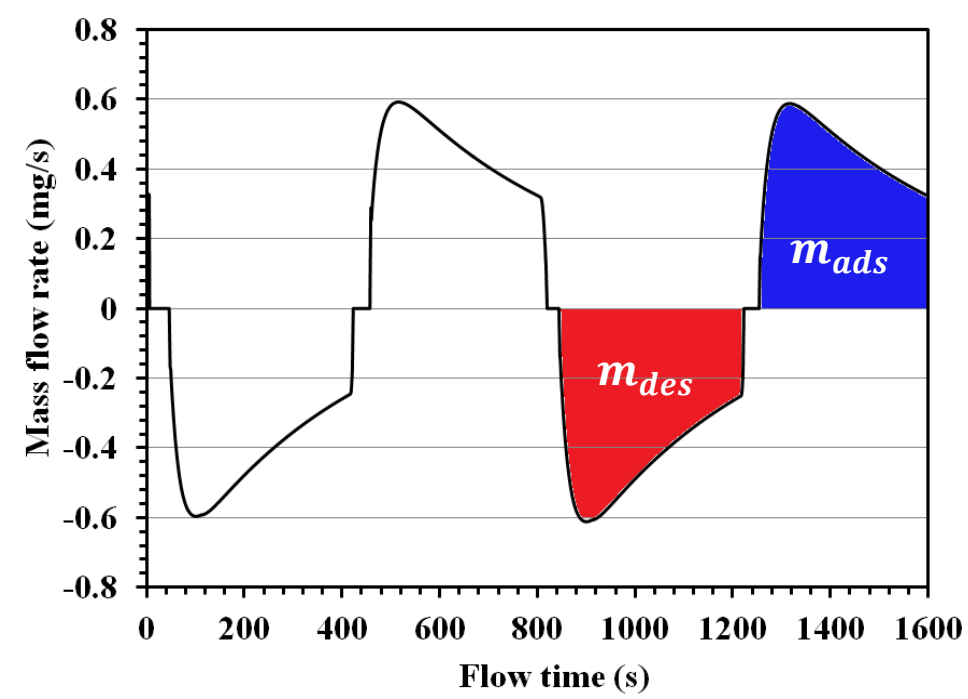

Figure 10. Simulated inlet/outlet mass flow rate to and from the adsorber for a volume between 2 fins.

\subsection{Performance Investigation}

The performance of adsorption cooling system (ACS) has been evaluated in terms of specific cooling power (SCP) and coefficient of performance (COP) by using Equations (13) and (14), correspondingly. The estimated SCP and COP for $800 \mathrm{~s}$ cycle time are found $488 \mathrm{~W} / \mathrm{kg}_{\mathrm{ac}}$ and 0.61 , respectively. This performance is also relevant to the reported performance for activated carbon-ethanol pair in other studies previously. The specific cooling capacity for activated-carbon ethanol pair considering two different particle size and three different domains has been reported between the range 
of 424 and $710 \mathrm{~W} / \mathrm{kg}_{\text {ac }}$ by Sourav et al. [24]. Besides, the performance of activated carbon fiber-ethanol based adsorption cooling system was found $200 \mathrm{~W} / \mathrm{kg}$ for SCP and 0.65 for COP previously [17].

Figure 11 shows the performance variation with cycle time. The COP increases with the increase of cycle time. However, the SCP reaches its maximum at a cycle time of $800 \mathrm{~s}$. With adsorption time increase, the cooling effect increases as the total mass adsorbed increases. However, the flow rate of adsorbed mass increases sharply at starting of adsorption then decreases as shown previously in Figure 10. Therefore the cooling power increases with cycle time increase and reaches its maximum at optimum cycle time of $800 \mathrm{~s}$. Then, for higher adsorption/desorption time, the cooling power decreases. The COP increases with adsorption/desorption time increase which as the increase in cooling effect generated is higher than the increase of heat consumed to desorb the refrigerant from activated carbon.

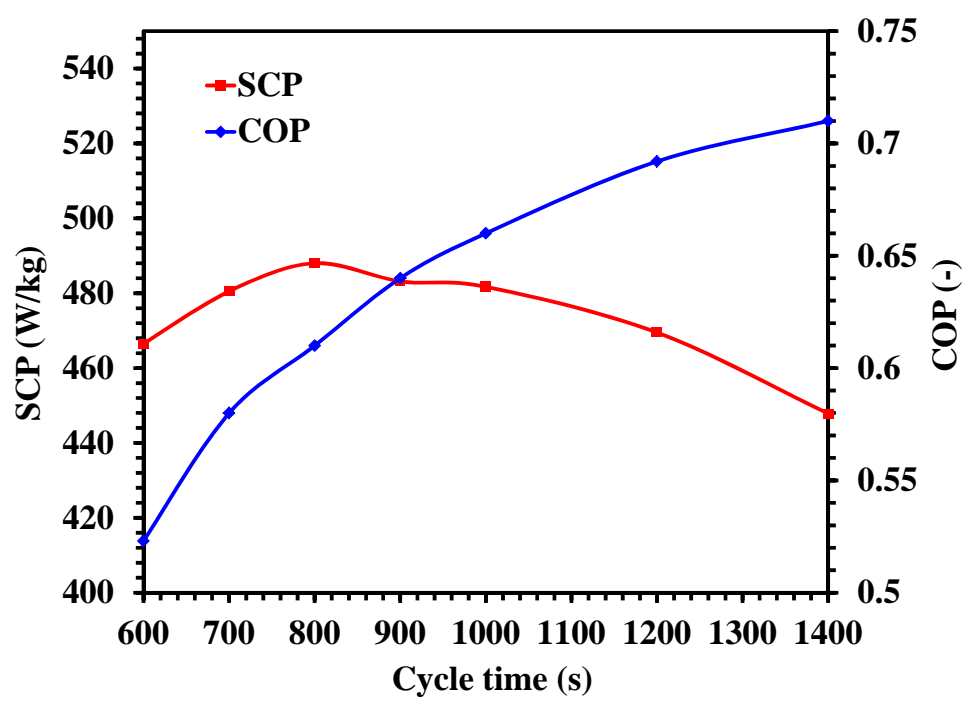

Figure 11. The variation of coefficient of performance (COP) and specific cooling power (SCP) with cycle time.

\section{Conclusions}

CFD modeling of a finned tube adsorber employing activated carbon-ethanol as the adsorbent-adsorbate pair has been performed. The simulated pressure and temperature profiles were compared with experimental data of an adsorption cooling system tested in our laboratory for evaporation temperature of $15^{\circ} \mathrm{C}$, cooling temperature of $20^{\circ} \mathrm{C}$, the heating temperature of $80^{\circ} \mathrm{C}$ and total cycle time of $800 \mathrm{~s}$. Good agreement was found between experimental and simulation results. The performance of the system was investigated numerically for different adsorption/desorption phase times ranging from 300 to $700 \mathrm{~s}$. The optimal cycle time for pre-heating and adsorption phases as well as pre-cooling and adsorption phases corresponded to $400 \mathrm{~s}$. At this condition, the cooling power reached $488 \mathrm{~W}$ per kilogram of adsorbent and the COP was 0.61. This CFD model will allow performance optimization of the system by optimizing the operating conditions as well as fin dimensions.

Author Contributions: M.K. and S.J. have equal contributions in CFD modeling and paper writing. T.M. has provided supervision and guidance in the simulation. B.B.S. and S.K. delivered overall guidance and were involved in the discussion.

Acknowledgments: The authors are thankful to the Green Asia Program, Kyushu University for providing research support and cooperation in all respects. Besides, this work is partially supported by research grant award for young researchers and doctoral students from Kyushu University Platform of Inter-/Transdisciplinary Energy Research (Q-PIT).

Conflicts of Interest: The founding sponsors had no role in the design of the study; in the collection, analyses, or interpretation of data; in the writing of the manuscript, and in the decision to publish the results. 


\section{Nomenclature}

\begin{tabular}{|c|c|}
\hline$A$ & pre-exponential factor $\left(\mathrm{s}^{-1}\right)$ \\
\hline C & inertial loss coefficient $\left(\mathrm{m}^{-1}\right)$ \\
\hline$D$ & diameter $(\mathrm{m})$ \\
\hline$E$ & energy $(\mathrm{kJ})$ \\
\hline$\vec{F}$ & force vector $(\mathrm{N})$ \\
\hline$\vec{g}$ & gravitational acceleration $\left(\mathrm{m} \cdot \mathrm{s}^{-2}\right)$ \\
\hline$h_{f g}$ & heat of evaporation $\left(\mathrm{J} \cdot \mathrm{kg}^{-1}\right)$ \\
\hline$k$ & diffusion time constant $\left(\mathrm{s}^{-1}\right)$ \\
\hline$n$ & heterogeneity parameter (-) \\
\hline$\dot{m}$ & mass flow rate $\left(\mathrm{kg} \cdot \mathrm{s}^{-1}\right)$ \\
\hline$m$ & mass $(\mathrm{kg})$ \\
\hline$p$ & pressure $(\mathrm{Pa})$ \\
\hline$R$ & gas constant $\left(\mathrm{kJ} \cdot \mathrm{kmol}^{-1} \cdot \mathrm{K}^{-1}\right)$ \\
\hline$S_{m}$ & mass source term $\left(\mathrm{kg} \cdot \mathrm{m}^{-3} \cdot \mathrm{s}^{-1}\right)$ \\
\hline$q$ & uptake $\left(\mathrm{kg} \cdot \mathrm{kg}^{-1}\right)$ \\
\hline$Q$ & thermal energy $(\mathrm{J})$ \\
\hline$Q_{s t}$ & heat of adsorption $\left(\mathrm{kJ} \cdot \mathrm{kg}^{-1}\right)$ \\
\hline$t$ & time (s) \\
\hline$T$ & temperature $(\mathrm{K})$ \\
\hline$v$ & velocity magnitude $\left(\mathrm{m} \cdot \mathrm{s}^{-1}\right)$ \\
\hline$\vec{v}$ & overall velocity vector $\left(\mathrm{m} \cdot \mathrm{s}^{-2}\right)$ \\
\hline \multicolumn{2}{|c|}{ Greek } \\
\hline$\alpha$ & permeability $\left(\mathrm{m}^{2}\right)$ \\
\hline$\gamma$ & porosity (-) \\
\hline$v_{\mu}$ & adsorbent' micropore volume $\left(\mathrm{cm}^{3} \cdot \mathrm{g}^{-1}\right)$ \\
\hline$\rho$ & density $\left(\mathrm{kg} \cdot \mathrm{m}^{-3}\right)$ \\
\hline$\mu$ & dynamic viscosity $(\mathrm{Pa} \cdot \mathrm{s})$ \\
\hline$\nabla$ & gradient \\
\hline$\overline{\bar{\tau}}$ & stress tensor $(\mathrm{Pa})$ \\
\hline \multicolumn{2}{|c|}{ Superscripts } \\
\hline * & equilibrium \\
\hline \multicolumn{2}{|c|}{ Subscripts } \\
\hline$a$ & apparent, activation \\
\hline$a c$ & activated carbon \\
\hline ads & adsorption \\
\hline chill & chill \\
\hline cond & condenser \\
\hline des & desorption \\
\hline eff & effective \\
\hline g & gas phase \\
\hline $\mathrm{p}$ & particle \\
\hline s & solid, saturated \\
\hline \multicolumn{2}{|c|}{ Acronyms } \\
\hline ACS & adsorption cooling system \\
\hline CFD & computational fluid dynamics \\
\hline NIST & National Institute of Standards and Technology \\
\hline SCP & specific cooling power \\
\hline $\mathrm{COP}$ & coefficient of performance \\
\hline
\end{tabular}




\section{References}

1. International Institute of Refrigeration. 35th Informatory Note on Refrigeration Technologies 'The Impact of the Refrigeration Sector on Climate Change'; International Institute of Refrigeration: Paris, France, 2017.

2. Umair, M.; Akisawa, A.; Ueda, Y. Performance evaluation of a solar adsorption refrigeration system with a wing type compound parabolic concentrator. Energies 2014, 7, 1448-1466. [CrossRef]

3. Hassan, H.Z. Performance evaluation of a continuous operation adsorption chiller powered by solar energy using silica gel and water as the working pair. Energies 2014, 7, 6382-6400. [CrossRef]

4. Pan, Q.W.; Wang, R.Z.; Wang, L.W.; Liu, D. Design and experimental study of a silica gel-water adsorption chiller with modular adsorbers. Int. J. Refrig. 2016, 67, 336-344. [CrossRef]

5. Uyun, A.S.; Miyazaki, T.; Ueda, Y.; Akisawa, A. Performance analysis of a double-effect adsorption refrigeration cycle with a silica gel/water working pair. Energies 2010, 3, 1704-1720.

6. Brancato, V.; Frazzica, A.; Sapienza, A.; Gordeeva, L.; Freni, A. Ethanol adsorption onto carbonaceous and composite adsorbents for adsorptive cooling system. Energy 2015, 84, 177-185. [CrossRef]

7. El-Sharkawy, I.I.; Hassan, M.; Saha, B.B.; Koyama, S.; Nasr, M.M. Study on adsorption of methanol onto carbon based adsorbents. Int. J. Refrig. 2009, 32, 1579-1586. [CrossRef]

8. Gong, L.X.; Wang, R.Z.; Xia, Z.Z.; Lu, Z.S. Experimental study on an adsorption chiller employing lithium chloride in silica gel and methanol. Int. J. Refrig. 2012, 35, 1950-1957. [CrossRef]

9. Li, S.L.; Xia, Z.Z.; Wu, J.Y.; Li, J.; Wang, R.Z.; Wang, L.W. Experimental study of a novel $\mathrm{CaCl}_{2} /$ expanded graphite- $\mathrm{NH}_{3}$ adsorption refrigerator. Int. J. Refrig. 2010, 33, 61-69. [CrossRef]

10. Jribi, S.; Saha, B.B.; Koyama, S.; Bentaher, H. Modeling and simulation of an activated carbon-CO four bed based adsorption cooling system. Energy Convers. Manag. 2014, 78, 985-991. [CrossRef]

11. Papakokkinos, G.; Bartrons, E.; Farnos, J.; Castro, J.; Oliva, A. A computational model based on parallelizable unstructured meshes for the simulation of the conjugate phenomena in the adsorption reactor. In Proceedings of the International Sorption Heat Pump Conference, Tokyo, Japan, 7-10 August 2017.

12. Demir, H.; Mobedi, M.; Ülkü, S. A review on adsorption heat pump: Problems and solutions. Renew. Sustain. Energy Rev. 2008, 12, 2381-2403. [CrossRef]

13. Wang, K.; Vineyard, E. Adsorption Refrigeration. ASHRAE J. 2011, 53, 14-24.

14. Wang, D.C.; Li, Y.H.; Li, D.; Xia, Y.Z.; Zhang, J.P. A review on adsorption refrigeration technology and adsorption deterioration in physical adsorption systems. Renew. Sustain. Energy Rev. 2010, 14, 344-353. [CrossRef]

15. Critoph, R.E. Forced convection adsorption cycles. Appl. Therm. Eng. 1998, 18, 799-807. [CrossRef]

16. Wang, D.C.; Xia, Z.Z.; Wu, J.Y. Design and performance prediction of a novel zeolite-water adsorption air conditioner. Energy Convers. Manag. 2006, 47, 590-610. [CrossRef]

17. Saha, B.B.; Chakraborty, A.; Koyama, S. Study on an activated carbon fiber e ethanol adsorption chiller: Part II e performance evaluation. Int. J. Refrig. 2007, 30, 96-102. [CrossRef]

18. Ali, S.M.; Chakraborty, A. Thermodynamic modelling and performance study of an engine waste heat driven adsorption cooling for automotive air-conditioning. Appl. Therm. Eng. 2015, 90, 54-63. [CrossRef]

19. Niazmand, H.; Dabzadeh, I. Numerical simulation of heat and mass transfer in adsorbent beds with annular fins. Int. J. Refrig. 2012, 35, 581-593. [CrossRef]

20. Mahdavikhah, M.; Niazmand, H. Effects of plate finned heat exchanger parameters on the adsorption chiller performance. Appl. Therm. Eng. 2013, 50, 939-949. [CrossRef]

21. Ramji, H.R.; Leo, S.L.; Abdullah, M.O. Parametric study and simulation of a heat-driven adsorber for air conditioning system employing activated carbon-methanol working pair. Appl. Energy 2014, 113, 324-333. [CrossRef]

22. Çağlar, A. The effect of fin design parameters on the heat transfer enhancement in the adsorbent bed of a thermal wave cycle. Appl. Therm. Eng. 2016, 104, 386-393. [CrossRef]

23. Jribi, S.; Miyazaki, T.; Saha, B.B.; Koyama, S.; Maeda, S.; Maruyama, T. CFD simulation and experimental validation of ethanol adsorption onto activated carbon packed heat exchanger. Int. J. Refrig. 2017, 74, 343-351. [CrossRef]

24. Mitra, S.; Muttakin, M.; Thu, K.; Saha, B.B. Study on the influence of adsorbent particle size and heat exchanger aspect ratio on dynamic adsorption characteristics. Appl. Therm. Eng. 2018, 133, 764-773. [CrossRef] 
25. Makimoto, N.; Kariya, K.; Koyama, S. Numerical analysis on adsorption characteristics of activated carbon/ethanol pair in finned tube type adsorber. Trans. JSRAE 2010, 27, 383-392.

26. Makimoto, N.; Hu, B.; Koyama, S. A study on thermophysical characteristices of activated carbon powder/ethanol pair in adsorber. In Proceedings of the International Sorption Heat Pump Conference, Padua, Italy, 6-8 April 2011; pp. 433-442.

27. Uddin, K.; Islam, M.A.; Mitra, S.; Lee, J.B.; Thu, K.; Saha, B.B.; Koyama, S. Specific heat capacities of carbon-based adsorbents for adsorption heat pump application. Appl. Therm. Eng. 2018, 129, 117-126. [CrossRef]

28. Chakraborty, A.; Saha, B.B.; Koyama, S.; Ng, K.C. Specific heat capacity of a single component adsorbent-adsorbate system. Appl. Phys. Lett. 2007, 90, 171902. [CrossRef]

29. ANSYS. Ansys Fluent User's Guide; ANSYS: Canonsburg, PA, USA, 2015.

30. Holaman, J.P. Heat Transfer, 10th ed.; McGraw-Hill: New York, NY, USA, 2010.

31. Uddin, K.; El-Sharkawy, I.I.; Miyazaki, T.; Saha, B.B.; Koyama, S.; Kil, H.S.; Miyawaki, J.; Yoon, S.-H. Adsorption characteristics of ethanol onto functional activated carbons with controlled oxygen content. Appl. Therm. Eng. 2014, 72, 211-218. [CrossRef]

32. Jribi, S.; Miyazaki, T.; Saha, B.B.; Koyama, S.; Maeda, S.; Maruyama, T. Corrected adsorption rate model of activated carbon-ethanol pair by means of CFD simulation. Int. J. Refrig. 2016, 71, 60-68. [CrossRef]

33. El-Sharkawy, I.I.; Uddin, K.; Miyazaki, T.; Saha, B.B.; Koyama, S.; Miyawaki, J.; Yoon, S.H. Adsorption of ethanol onto parent and surface treated activated carbon powders. Int. J. Heat Mass Transf. 2014, 73, 445-455. [CrossRef]

34. Ambrose, D.; Sprake, C.H.S. Thermodynamic properties of organic oxygen compounds XXV. Vapour pressures and normal boiling temperatures of aliphatic alcohols. J. Chem. Thermodyn. 1970, 2, 631-645. [CrossRef]

(C) 2018 by the authors. Licensee MDPI, Basel, Switzerland. This article is an open access article distributed under the terms and conditions of the Creative Commons Attribution (CC BY) license (http:/ / creativecommons.org/licenses/by/4.0/). 